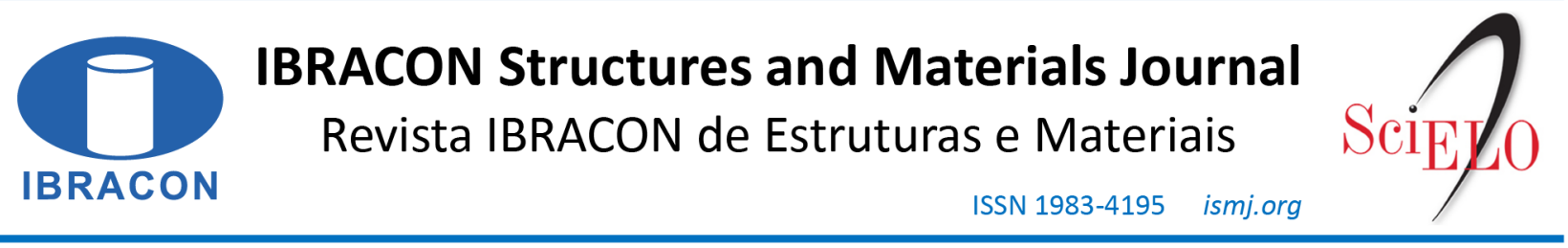

ORIGINAL ARTICLE

\title{
Structural analysis of pile cap as onshore wind turbine foundation
}

\section{Análise estrutural de blocos sobre estacas como fundação para aerogerador onshore}

\author{
Kaique Yuri Marcio Araújo ${ }^{\mathrm{a}}$ (D) \\ Rodrigo Barros ${ }^{\mathrm{b}}$ \\ Joel Araújo Nascimento Neto ${ }^{\mathrm{b}}$
}

${ }^{a}$ Instituto Federal de Educação, Ciência e Tecnologia do Rio Grande do Norte - IFRN, Campus Mossoró, Mossoró, RN, Brasil

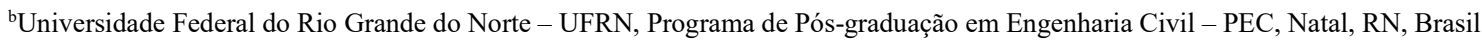

Received 19 September 2019

Accepted 20 October 2020

\begin{abstract}
This paper analyzes the structural behavior of reinforced concrete pile caps as onshore wind turbine foundations using eight models based on the finite element method (FEM). The variables adopted are: the type of finite element utilized; the soil representation; and, considering or not the soil under the pile cap base. All materials constituting the models were considered as linear elastic behavior. The results of interest are: reaction in piles; dividing the load between soil and piles; pile cap displacement; normal radial stress and bending moments in the pile cap. The models designed on solid elements and shell elements demonstrated good compatibility between the found values, such as dividing the load between soil and piles. In some models, the numerical analysis showed results against the structural safety of the foundation when the soil under the pile cap is not considered.
\end{abstract}

Keywords: pile cap, wind turbine foundation, structural analysis, finite element method.

Resumo: Este artigo analisa o comportamento estrutural de blocos de concreto armado sobre estacas como fundações de aerogeradores onshore por meio de oito modelos baseados no Método dos Elementos Finitos. Foram adotadas como variáveis: o tipo de elemento finito utilizado; o tipo de representação do solo; e, a consideração ou não da resistência do solo sob a base do bloco. Os materiais foram tratados com modelos constitutivos de comportamento elástico linear. Os resultados de interesse foram: reações nas estacas; divisão do carregamento entre o solo e as estacas; deslocamento do bloco; tensões normais radiais e momentos fletores no bloco. Na comparação entre os modelos em elementos sólidos e elementos de casca foi observado que houve boa compatibilidade entre os valores encontrados, tais como divisão do carregamento entre solo e estacas. Em alguns modelos, as análises numéricas revelaram resultados que podem ser contra a segurança estrutural da fundação, quando não se considera a presença do solo sob a base do bloco.

Palavras-chave: bloco sobre estacas, fundação de aerogerador, análise estrutural, método dos elementos finitos.

How to cite: K. Y. M. Araújo, R. Barros, and J. A. Nascimento Neto, "Structural analysis of pile cap as onshore wind turbine foundation," Rev. IBRACON Estrut. Mater., vol. 14, no. 5, e14504, 2021, https://doi.org/10.1590/S1983-41952021000500004

\section{INTRODUCTION}

The expanding wind energy industry in Brazil has required large size foundation projects, which in most cases are pile caps. The construction of these structural elements demands more than 300 cubic meters of concrete and 20 tons of steel. In this context, a deeper analysis of these RC foundations can collaborate with the improvement of these projects, which are especially relevant for developing the Brazilian energy matrix. 
In this regard, the early studies of structural analysis of wind turbines focused on the dynamic analysis of offshore wind turbines and were essential for the calibration of theoretical curves of lift and drag coefficients, such as in Sinclair and Clayton [1].

van der Tempel and Molenaar [2] carried out an analytical study of real situations of offshore wind turbines under the action of waves, based on the theory of dynamic analysis, and concluded that more flexible structures are cheaper, but the dynamics phenomena need to be treated with more attention.

Adhikari and Bhattacharya [3] analyzed the vibration of offshore wind turbines, including the contribution of the foundation. They compared analytical models, analogous to the Euler-Bernoulli beam, with an experimental model, and showed that the natural frequency of the tower decreases with the reduction of the foundation stiffness and with increased axial load.

The improvement of personal computers and the advent of the Finite Element Method (FEM) allowed to carry out analyses with robust numerical models, such as the study of Satari and Hussain [4], which compared the vibration frequency of wind turbines with shallow and deep foundations.

Moura et al. [5] used geotechnical data from a dune soil (from two beaches on the coast of the state of Ceará, Brazil) to estimate the natural vibration frequency of a shallow foundation of $500 \mathrm{~kW}$ wind turbine using different analytical methods. In that study, the estimates for natural vibration frequency ranged from 385 to $1529 \mathrm{rpm}$.

Ribeiro et al. [6] analyzed the fatigue in shallow and deep foundations of wind turbines based on FEM and concluded that the fatigue considerations used in bridge designs can be extended to the design of wind turbine foundations, considering the specific aspects of these structures.

Araújo et al. [7] evaluated spread footing as wind turbines foundation, comparing numerical models built with shell and solid elements, and showed the importance of solid models to analyze stress field of the structural element of the foundations.

Maranhão [8] analyzed the rotational stiffness of a deep foundation (piles) as support for an onshore wind turbine through different finite element numerical models and proposed an analytical model for calculating the rotational stiffness for the type of foundation analyzed.

Within this context, this paper aims to make a comparison between numerical models of circular pile cap, as foundation for onshore wind turbines, by FEM. The focus of this study is to evaluate the compatibility of the structural behavior of pile caps in some models based on FEM, especially when considering the resistance of the soil in contact with the base of the pile cap.

\subsection{Pile caps for wind turbines}

In the design of pile caps, structural engineers usually do not consider the contribution of the pile cap base in contact with soil. However, in cases of large size pile caps, like the bases of onshore wind turbines, the direct load transmission of this element to the ground can be relevant, which becomes a mixed foundation, distributing the loads to the soil both by the base of the pile cap and by the pile group.

The main problem to design pile caps when considering a mixed system, that is, considering the contribution of the soil under the base of the pile cap, regards evaluating its real functioning mechanism, where it is difficult to accurately represent, using analytical models (strut-and-tie or classical beam theory), the complex behavior of this structural system, as well as its physical configuration at rupture.

\section{STRUCTURAL DESCRIPTION}

Static analysis of RC circular pile caps was performed using the ANSYS and SAP2000 software, based on FEM, considering linear elastic behavior of the constitutive material of the models. Twenty-four piles were distributed around the pile cap. The models were developed with and without the soil under the pile cap base.

For the models developed using ANSYS, the soil was represented by a continuous medium, while for the models developed using SAP2000, they were modeled according to the Winkler approach.

When the soil was represented by a continuous medium, it was modeled as a solid with a linear elastic behavior.

According to Velloso and Lopes [9], the Winkler approach establishes that the reactive pressure is proportional to the spring deflection, in a direct relation. What defines the magnitude of this relationship is the so-called "modulus of subgrade reaction", represented by $\mathrm{k}_{\mathrm{v}}$.

In this paper, a unique geometry was considered as a reference to design all models created on both the ANSYS and the SAP2000. The pile cap has a diameter (D) of $14.50 \mathrm{~m}$, with 24 piles distributed around a circle with a diameter $\left(D_{\text {pile }}\right)$ of $13.00 \mathrm{~m}$. The pedestal, the central part of the pile cap, has a height $(\mathrm{H})$ of $3.00 \mathrm{~m}$ and a diameter of $6.00 \mathrm{~m}$. 
The tilted part of the pile cap has a varying height from (h0) $1.20 \mathrm{~m}$ to (h1) $1.80 \mathrm{~m}$, as shown in Figure 1 . The pile cap is supported on 24 piles of $41 \mathrm{~cm}$ diameter, resulting in a cross-section area of $1,320.25 \mathrm{~cm}^{2}$, and a length of $10.00 \mathrm{~m}$.

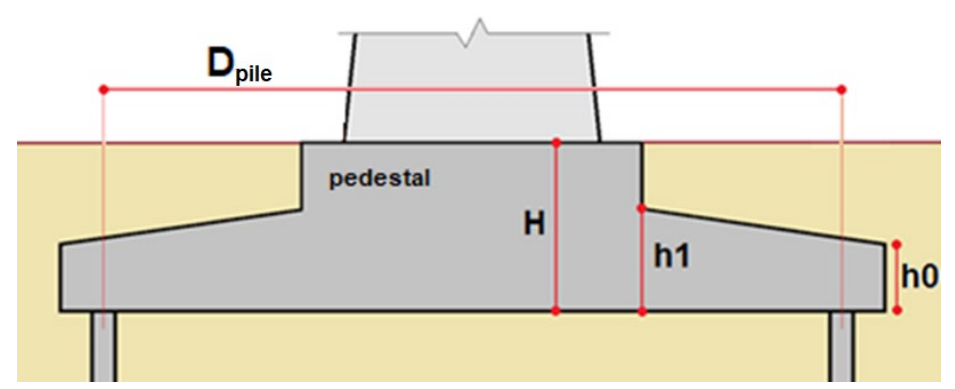

Figure 1. Geometry of the pile cap.

The ANS models used piles with polygonal cross section (with an area of 2,126.60 $\mathrm{cm}^{2}$ ) to make the finite element meshes compatible with the different components of the model, as shown in Figure 2. As a result, it was necessary to reduce the pile modulus of elasticity $\left(\mathrm{E}_{\mathrm{cs}, \text { pile }}\right) 1.61$ times (ratio between the pile cross section areas: $2,126.60 / 1,320.25$ ) to equalize the axial deformations in both cases.

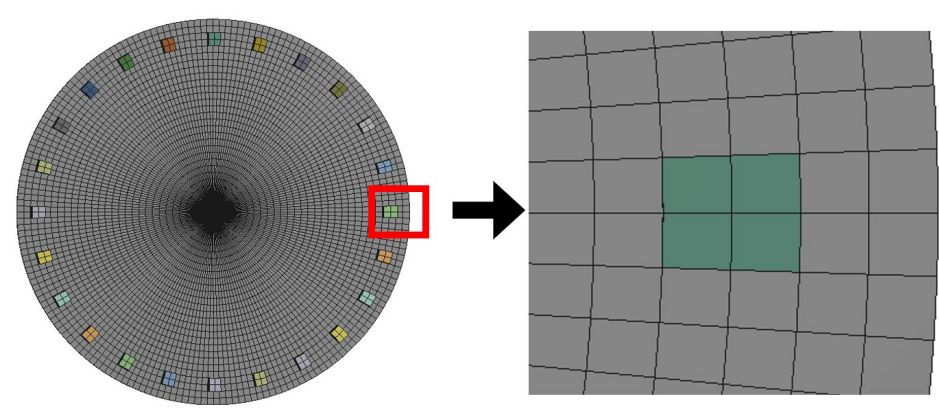

Figure 2. Detail of piles with polygonal cross section for all ANS models.

Figure 3 shows the model made on the ANSYS, in which the soil was modeled by a cylindrical soil mass (diameter of $30 \mathrm{~m}$ and height of $30 \mathrm{~m}$ ). Such dimensions were adopted based on Love's proposition [10] for the Boussinesq method, which shows that the addition of vertical stress in the soil at a depth of 2D, induced by a uniformly distributed load (p) in a circular area (of diameter $\mathrm{D}$ ), is in the order of $0.05 \mathrm{p}$, and the horizontal stress increment spreads radially up to $1.5 \mathrm{D}$ from the center of the load. Furthermore, the vertical domain of the soil mass is three times the length of the piles, which is considered reasonable.

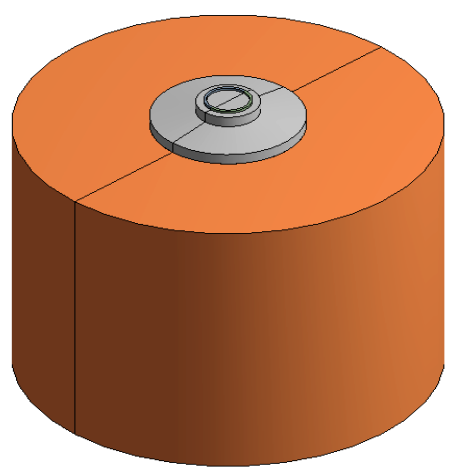

Figure 3. Cylindrical soil mass for the ANS-S1, ANS-S2 and ANS-S3 models. 
For all models, a ring with rigid behavior was used only at the cross section of the pile cap-tower, called in this paper as the "load ring", to minimize the stress concentration due to the loads coming from the wind tower, as well as to represent the high stiffness of the tower wall. This ring is $4.25 \mathrm{~m}$ internal diameter and $4.50 \mathrm{~m}$ external diameter.

Eight finite elements models were produced for the numerical simulation, all based on the same reference geometry previously presented, four using ANSYS and four using SAP2000. Table 1 summarizes the characteristics of the models, indicating the type of finite element used, as well as the support conditions considered.

Table 1. Models' characteristics.

\begin{tabular}{ccccc}
\hline \multirow{2}{*}{ Models } & Software & \multicolumn{3}{c}{ Finite elements } \\
\cline { 3 - 5 } & ANSYS & Pile Cap & Pile & Soil \\
\hline ANS-S0 & ANSYS & Solid & Solid & Solid: Esoil,1 \\
\hline ANS-S1 & SNSYS & Solid & Solid & Solid: Esoil,2 \\
\hline ANS-S2 & ANSYS & Solid & Solid & Solid: E Eoil,3 \\
\hline ANS-S3 & SAP2000 & Shell & Spring & - \\
\hline SAP-S0 & SAP2000 & Shell & Spring & Elastic Base: $\mathrm{k}_{\mathrm{v} 1}$ \\
\hline SAP-S1 & SAP2000 & Shell & Spring & Elastic Base: $\mathrm{k}_{\mathrm{v} 2}$ \\
\hline SAP-S2 & SAP2000 & Shell & & Elastic Base: $\mathrm{k}_{\mathrm{v} 3}$ \\
\hline SAP-S3 & & &
\end{tabular}

The concrete parameters were adopted according to the recommendations of the ABNT NBR 6118:2014 [11], where the Poisson's ratio was (v) 0.20 and the secant modulus of elasticity: $\mathrm{E}_{\mathrm{cs}, \mathrm{pc}}=27,000 \mathrm{MPa}$ (for $\mathrm{C} 30$ concrete), for the pile cap; and, $\mathrm{E}_{\mathrm{cs}, \mathrm{pile}}=21,000 \mathrm{MPa}$ (for $\mathrm{C} 20$ concrete), for the piles. The pile secant modulus of elasticity was adjusted for the ANS models, considering the cross section was modeled as polygonal shape, to $\mathrm{E}_{\text {(cs,pile') }}=13,043.48 \mathrm{MPa}$.

For the SAP models, the piles were modeled as elastic supports, with spring coefficient $\mathrm{k}_{\text {pile }} 277,253.41 \mathrm{kN} / \mathrm{m}$, equivalent to a pile of: diameter of $41 \mathrm{~cm}$, length of $10 \mathrm{~m}$ and a concrete secant modulus of elasticity of $\mathrm{E}_{\mathrm{cs}, \mathrm{pile}}=21,000$ $\mathrm{MPa}$. As the objective of this paper is to evaluate the pile cap structural behavior, this simplification was used, which does not consider foundation settlement from the geotechnical element.

Poisson's ratio of $v=0.35$ was considered for the soil in all models.

For the ANS-S1, ANS-S2 and ANS-S3 models the modulus of elasticity adopted for the soil ( $\left.\mathrm{E}_{\text {soil }}\right)$ is as follows:

- $\mathrm{E}_{\text {soil }, 1}=20 \mathrm{MPa}$ (loose sand);

- $\mathrm{E}_{\text {soil, }}=50 \mathrm{MPa}$ (medium sand);

- $\mathrm{E}_{\mathrm{soil}, 3}=100 \mathrm{MPa}$ (dense sand).

The modulus of elasticity for the soil was defined based on the values suggested by Poulos [12], Poulos and Davis [13] and Teixeira and Godoy [14]. Equation 1 was used as proposed by Boussinesq [15], to correlate the modulus of subgrade reaction $\left(\mathrm{k}_{\mathrm{v}}\right)$ with the modulus of elasticity $\left(\mathrm{E}_{\mathrm{soil}}\right)$, for the soil. It is worth mentioning that the modulus of subgrade reaction is not a property of the soil, as it depends on the geometry of the foundation.

$$
\mathrm{k}_{\mathrm{v}}=\frac{2 \cdot \mathrm{E}_{\mathrm{s}}}{\mathrm{R} \cdot \pi \cdot\left(1-\mathrm{v}^{2}\right)}
$$

Thus, for the SAP-S1, SAP-S2 and SAP-S3 models the modulus of subgrade reaction for the soil $\left(\mathrm{k}_{\mathrm{v}}\right)$ adopted is as follows:

- $\mathrm{k}_{\mathrm{v} 1}=2,000 \mathrm{kN} / \mathrm{m}^{3}$ (loose sand);

- $\mathrm{k}_{\mathrm{v} 2}=5,000 \mathrm{kN} / \mathrm{m}^{3}$ (medium sand);

- $\mathrm{k}_{\mathrm{v} 3}=10,000 \mathrm{kN} / \mathrm{m}^{3}$ (dense sand).

\section{MODELING AND ANALYSIS}

Similar physical and geometric characteristics were adopted for numerical modeling in both software, such as: geometry, loading and mechanical parameters of the concrete. The difference was in the types of finite elements used for the models in each of the software, where solid elements were used on the ANSYS and shell elements on the 
SAP2000. It is worth mentioning that only the pile caps modeled with solid elements shows the stress field in three dimensions, which can useful to define a strut-and-tie model.

As the model with shell elements is simpler to make and to process than the model with solid elements, which requires higher computational effort, there was interest in studying the influence of the choice of the finite element type on the results of: reaction in piles; bending moment, pile cap stress and displacement; as well as performing a comparative analysis about the influence of soil modeling as a spring set compared to a model that simulates the continuous medium.

For the ANS models, six and eight nodes solid elements were used to model all components (pile cap, piles and soil). For the ANS-S0 model, there was no soil under the pile cap base. For the ANS-S1, ANS-S2 and ANS-S3 models the soil was modeled as a cylindrical soil mass made with solid elements. For all ANS models, the structural element of the foundation (pile cap + piles) was modeled with solid elements.

Table 2 shows the contact types, as well as their behaviors, available on the ANSYS. Thus, we adopted the contact types for the ANS models as follows: 1) bonded: for pile cap-piles and pile cap-loading ring; and, 2) frictionless: for soil-pile cap and soil-piles.

Table 2. Contact types and behaviors in Ansys.

\begin{tabular}{ccc}
\hline \multirow{2}{*}{ Contact types } & \multicolumn{2}{c}{ Behavior } \\
\cline { 2 - 3 } & Gap & Sliding \\
\hline Bonded & No & No \\
\hline No Separation & No & Yes, $\mu=0$ \\
\hline Rough & Yes & No, $\mu=\infty$ \\
\hline Frictionless & Yes & Yes, $\mu=0$ \\
\hline Frictional & Yes & Yes, $\mu>0$ \\
\hline
\end{tabular}

$\mu$ : coefficient of friction (dimensionless scalar value)

For the ANS-S1, ANS-S2 and ANS-S3 models, the axial pile capacity, composed by side friction and end-bearing resistance, was taken as a single resistance at the pile tip to maximize the actions of the pile cap base. This is because if the side friction was considered, the piles would become more rigid and, consequently, they would receive a larger part of the loads, reducing the part that would go directly to the soil under the pile cap base. Thus, a fixed support was defined at the bottom tip of all 24 piles (this situation is possible, for example, when piles are supported on rocks), as well as at the base of the cylindrical soil mass, restricting displacements and rotations.

For the ANS models, a finite element mesh of $25 \mathrm{~cm}$ (average spacing between nodes) was used for the pile cap, piles (only in the cross-section plane) and cylindrical soil mass (only under the pile cap). In addition, a mesh of $250 \mathrm{~cm}$ vertical space and $100 \mathrm{~cm}$ horizontal space was defined for the soil mass around of the pile cap. The same vertical space was used for the piles. Figure 4 shows the details of discretization for the ANS models.
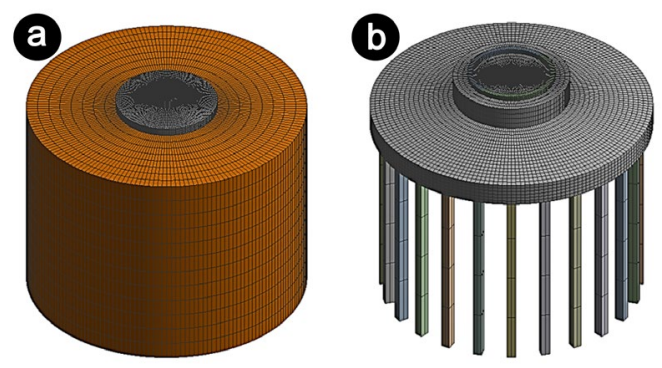

Figure 4. Discretization of the ANS models: detail of cylindrical soil mass (a); detail of pile cap (b).

For the SAP models, three and four node shell elements (thin plate type) were used to model the pile cap. The piles were modeled as discrete springs with linear elastic behavior in the vertical direction and set in the horizontal plane. For the SAP-S1, SAP-S2 and SAP-S3 models the soil was modeled as an elastic base, that is, with a group of compression only springs. For all these models, rigid constrains were used in the nodes of the load ring region. For the SAP models, a finite element mesh of $25 \mathrm{~cm}$ was utilized, in the radial direction, and varying from 0 to $95 \mathrm{~cm}$ in the tangential direction. Figure 5 shows the discretization details for the SAP models. 

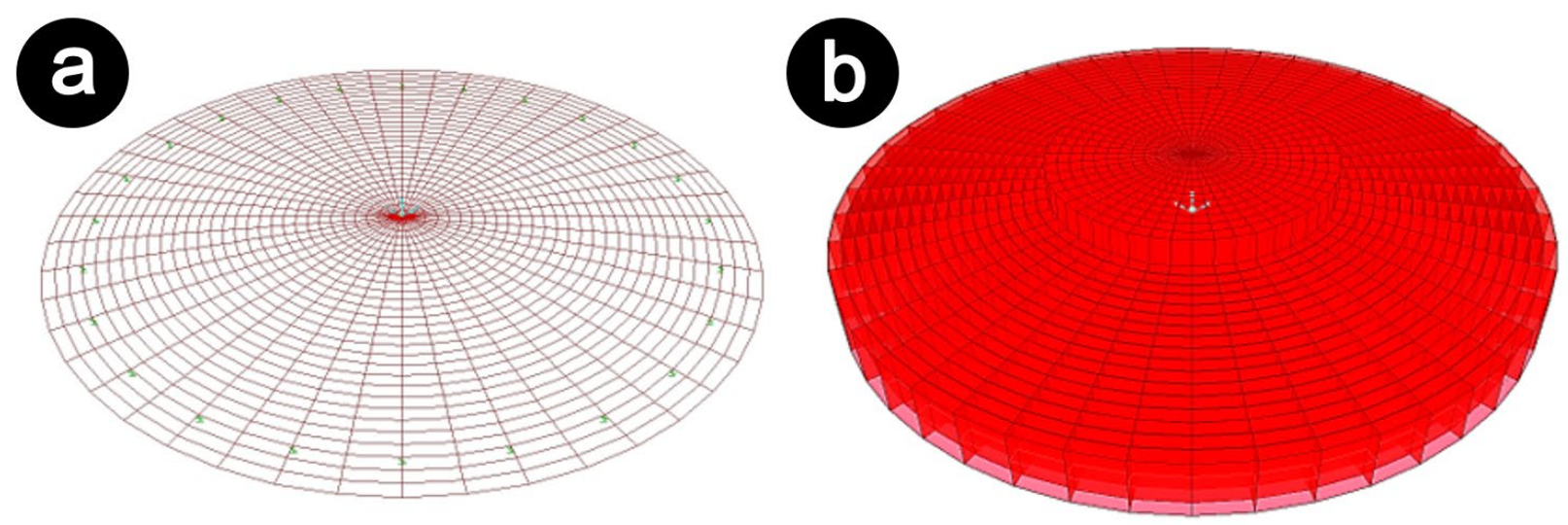

Figure 5. Discretization of pile cap for all the SAP models: standard view (a); extruded (b).

For this paper, typical loads of 2 to $3 \mathrm{MW}$ wind turbines were adopted. The loads acting on the foundation are: horizontal force $\mathrm{F}_{\mathrm{xy}}$ (referring to the result of horizontal forces acting on the XY plane); moment $\mathrm{M}_{\mathrm{xy}}$ (resulting from the moments acting around $\mathrm{X}$ and $\mathrm{Y}$ axes) and vertical force $\mathrm{F}_{\mathrm{z}}$ due to gravitational loads.

Table 3 presents the characteristic values adopted for the loads acting on the pile cap due to the wind turbine of $86 \mathrm{~m}$ rotor diameter and $80 \mathrm{~m}$ height (steel tower), as well as the loads that act on it in a power generation situation with extreme wind speed, with a 50-year recurrence period. In addition to these loads, a specific weight of $24 \mathrm{kN} / \mathrm{m}^{3}$ was considered for the pile cap concrete and $16 \mathrm{kN} / \mathrm{m}^{3}$ for the landfill. Thus, the self-weight of the pile cap resulted in $6,826 \mathrm{kN}$ and the landfill weight on it was $1,957 \mathrm{kN}$.

Table 3. Loads acting on the pile cap due to the wind turbine and loads that act on it in a power generation situation with extreme wind speed, with a 50-year recurrence period.

\begin{tabular}{ccc}
\hline Type of loads & Operational loads & Extreme loads \\
\hline Vertical force $-\mathrm{F}_{\mathrm{z}}(\mathrm{kN})$ & 2417 & 2478 \\
\hline Horizontal Force $-\mathrm{F}_{\mathrm{xy}}(\mathrm{kN})$ & 376 & 622 \\
\hline Moment $-\mathrm{M}_{\mathrm{xy}}(\mathrm{kN} \cdot \mathrm{m})$ & 26918 & 45066 \\
\hline
\end{tabular}

Note: The self-weight of the pile cap and the landfill weight are not accounted in the table above.

To simplify the analysis, without damaging the research objectives, all the loads considered (vertical and horizontal force, moment, self-weight and landfill weight) were combined with their characteristic values, that is, with partial factor for loads of $\gamma_{\mathrm{fi}}=1.00$.

The moment considered when the pile cap-tower encountered the block was the total tipping moment $\left(\mathrm{M}_{\text {total }}\right)$, which is composed of the sum of the $\mathrm{M}_{\mathrm{xy}}$ moment and the additional moment caused by the cutting force $\mathrm{F}_{\mathrm{xy}}$ in relation to the tipping axis of the base, taken as the center of the lower face of the block (O), as shown in Figure 6. Thus, the total moment is given by Equation 2.

$\mathrm{M}_{\text {total }}=\mathrm{M}_{\mathrm{xy}}+\mathrm{F}_{\mathrm{xy}} \cdot \mathrm{H}$

Applying the values in Equation 2, the total tipping moment results in: $\mathrm{M}_{\text {total }}=46,932 \mathrm{kN} \cdot \mathrm{m}$. 


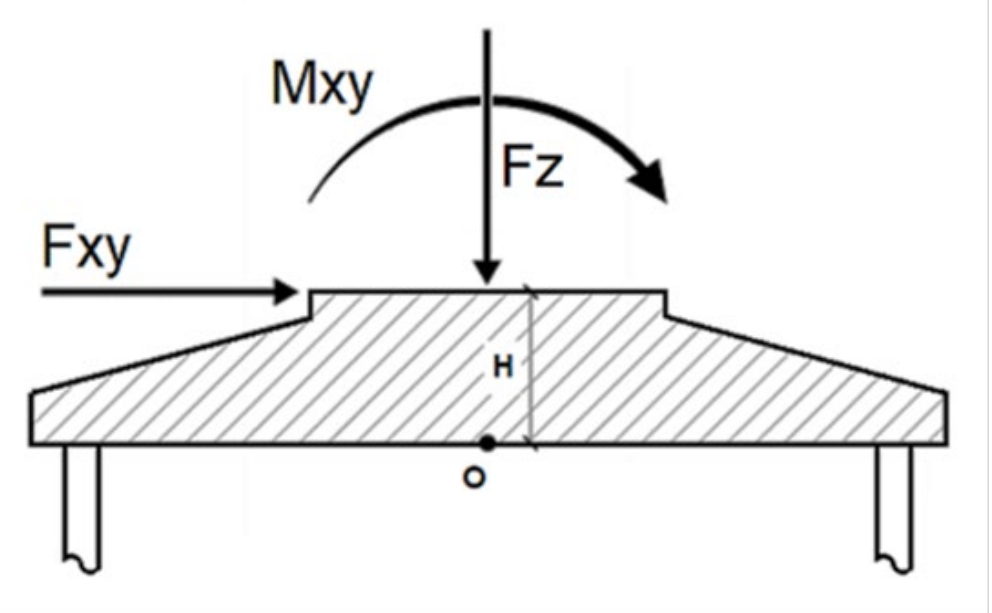

Figure 6. Representation of loads transmitted from the wind turbine tower to the pile cap.

The direct action of the horizontal force $\left(\mathrm{F}_{\mathrm{xy}}\right)$ was not considered for all models, only considering its tipping effect due to the additional moment $\left(\mathrm{F}_{\mathrm{xy}} \cdot \mathrm{H}\right)$. This was due to the complexity in calculating the passive earth pressure on the side of the pile cap, as well as the pile cap-soil friction, which would act opposite to the horizontal force. Thus, its application could lead to horizontal reaction in piles that would not be compatible with reality. In addition, the ANS and SAP models present lateral displacement of the pile cap that are very different from each other, due to their particular modeling aspects. That said, the horizontal force was not considered for the sake of a better comparative analysis between all models.

For the SAP models, concentrated loads (representing the action from the tower) were applied on 24 nodes located in the load ring. For the ANS models, the loads were applied directly to the upper surface of the load ring as a distributed load.

The landfill weight was applied as a distributed load over the pile cap (on the surface outside the pedestal), with a value of $14.30 \mathrm{kN} / \mathrm{m}^{2}$.

\section{RESULTS}

Figure 7 shows the numbering defined for the 24 piles, as well as the local axis system (in cylindrical coordinates) used as a reference for all analyses performed in this paper. Axis 3 is in the perpendicular direction to the 1-2 axes plane, in the direction exiting the figure.

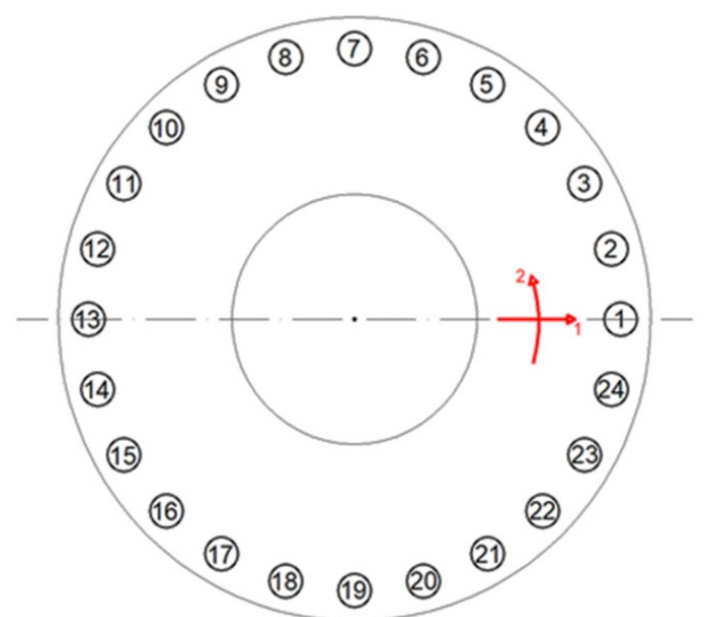

Figure 7. Piles numbering and local axis system. 
Table 4 presents the results of reaction in piles, obtained for all the models analyzed. The reaction in piles in the "Analytical" column was obtained by an analytical approach, superimposing force and moment applied to the pile cap, using Equation 3, initially proposed by Schiel [16], which is based on the compatibility of displacements, not considering the group effect of the piles. This method is widely used by structural engineers, and recommended by Alonso [17]. It was assumed that the pile cap was infinitely rigid, that the $\mathrm{x}$ and $\mathrm{y}$ were principal axes and that the piles were all identical and vertical without inclination.

$R_{\text {pilet,i }}=\frac{F_{z}}{n}+\frac{M_{y} \cdot x_{i}}{\sum x_{i}^{2}}+\frac{M_{x} \cdot y_{i}}{\sum y_{i}^{2}}$

where:

$\mathrm{R}_{\text {pile, }}$ - Vertical reaction in piles for the "i-pile", with $\mathrm{x}_{\mathrm{i}}$ and $\mathrm{y}_{\mathrm{i}}$ coordinates;

$F_{z}-$ Resulting vertical force (including the pile cap self-weight and the landfill weight);

$\mathrm{n}$ - Number of piles;

$\mathrm{M}_{\mathrm{x}}-$ Moment of x-axis;

$\mathrm{M}_{\mathrm{y}}-$ Moment of y-axis.

Table 4. Reactions in piles obtained by the analytical approach and by the numerical models.

\begin{tabular}{|c|c|c|c|c|c|c|c|c|c|}
\hline \multirow{2}{*}{ Pile } & \multicolumn{9}{|c|}{ Reaction in Piles (kN) } \\
\hline & Analytical & ANS-S0 & ANS-S1 & ANS-S2 & ANS-S3 & SAP-S0 & SAP-S1 & SAP-S2 & SAP-S3 \\
\hline 1 & 1074.70 & 1070.80 & 1014.40 & 936.74 & 830.68 & 1063.41 & 1018.30 & 950.56 & 857.46 \\
\hline 2 & 1054.19 & 1050.30 & 995.04 & 918.95 & 814.98 & 1042.90 & 998.50 & 931.73 & 840.02 \\
\hline 3 & 994.11 & 990.32 & 938.41 & 866.75 & 768.85 & 982.79 & 940.45 & 876.49 & 788.87 \\
\hline 4 & 898.57 & 894.85 & 848.28 & 783.63 & 695.33 & 887.17 & 848.11 & 788.62 & 707.50 \\
\hline 5 & 774.03 & 770.43 & 730.66 & 675.04 & 599.11 & 762.56 & 727.75 & 674.09 & 601.45 \\
\hline 6 & 629.00 & 625.54 & 593.45 & 548.12 & 486.32 & 617.44 & 587.60 & 540.72 & 477.93 \\
\hline 7 & 473.38 & 470.05 & 445.81 & 411.12 & 363.97 & 461.71 & 437.18 & 397.57 & 345.32 \\
\hline 8 & 317.76 & 314.57 & 297.60 & 272.93 & 239.55 & 305.98 & 286.74 & 254.35 & 212.58 \\
\hline 9 & 172.73 & 169.67 & 158.83 & 142.68 & 120.98 & 160.86 & 146.52 & 120.78 & 88.61 \\
\hline 10 & 48.19 & 45.25 & 39.15 & 29.63 & 17.02 & 36.24 & 26.04 & 5.90 & -18.09 \\
\hline 11 & -47.35 & -50.22 & -52.96 & -57.81 & -64.01 & -59.38 & -66.38 & -82.13 & -99.84 \\
\hline 12 & -107.43 & -110.23 & -110.98 & -113.06 & -115.46 & -119.49 & -124.50 & -137.56 & -151.45 \\
\hline 13 & -127.94 & -130.70 & -130.78 & -131.94 & -133.10 & -139.99 & -144.34 & -156.50 & -169.10 \\
\hline
\end{tabular}

Figure 8 shows comparisons between the reaction in piles for the corresponding piles in both ANS and SAP models, case by case. This figure presents, as a reference, the reaction in piles obtained by the analytical approach. 


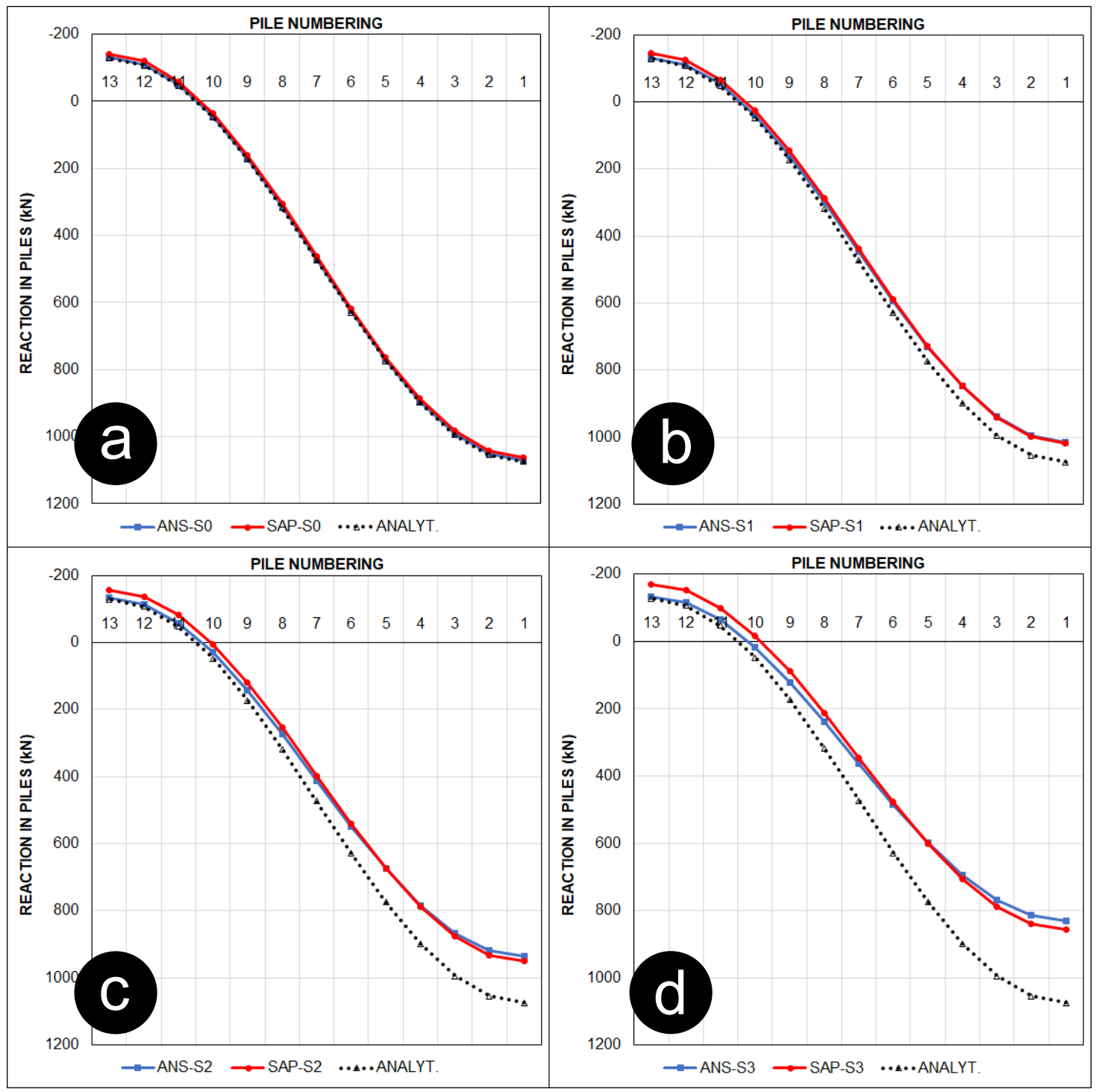

Figure 8. Reaction in piles for all the models, presented in equivalent pairs: ANS-S0 and SAP-S0 (a); ANS-S1 and SAP-S1 (b); ANS-S2 and SAP-S2 (c); ANS-S3 and SAP-S3 (d).

Based on Figure 8, it was found that the reaction in piles for the ANS-S0 and SAP-S0 models showed close values to each other, as well as with those calculated by the analytical approach. This was an expected result, considering the assumptions that were adopted in the models. In addition, it was observed that the reaction in piles for the ANS-S1 and SAP-S1 models was also nearly coincidental. In relation to the previous models, the pairs ANS-S2 and SAP-S2, as well as ANS-S3 and SAP-S3, indicated divergences between them, especially for the most tensile and compressed piles. Comparing the ANS-S2 and SAP-S2 models, the second one presented $18.61 \%$ higher maximum tensile reaction and $1.48 \%$ higher maximum compression reaction (in module). Comparing the ANS-S3 and SAP-S3 models, the second one presented $27.05 \%$ higher maximum tensile reaction and $3.22 \%$ higher maximum compression reaction (in module).

Based on Figure 8, the SAP models show a tendency to increase the tensile modulus of the reactions in piles 11, 12 and 13 with the increase in soil stiffness. From this perspective, the results presented may be contrary to the structural security of the foundation when the presence of soil under the pile cap base is not considered in the model. This is because the presence of soil under the pile cap causes a decrease in the portion of compressive load that goes directly to the piles, and tensioning at that moment.

Figure 9 shows the sum of reactions in piles for each of the models analyzed in this paper, as well as the sum of reactions in piles obtained by the analytical approach. 


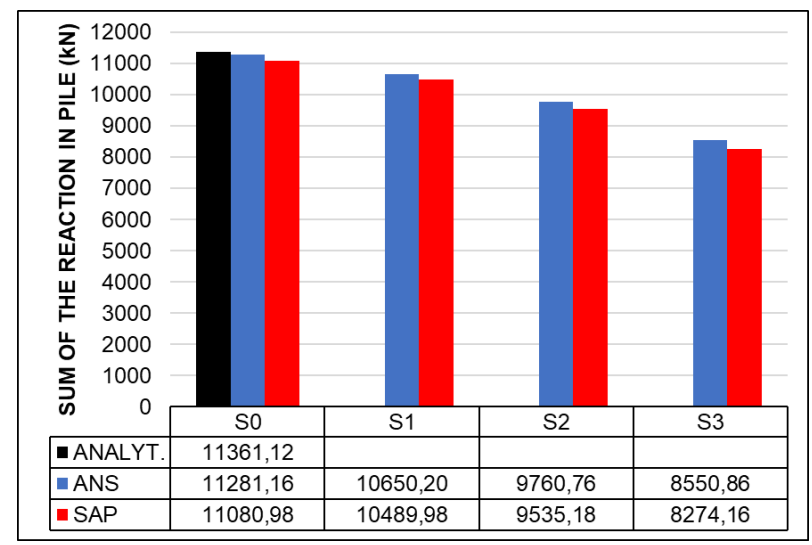

Figure 9. Total sum of reactions in piles for all models.

Considering the premises adopted in this paper, Figure 9 shows that the vertical load that goes to the piles is reduced with the increase in soil stiffness, decreasing from $11,281.16 \mathrm{kN}$ in the ANS-S0 model (less soil stiffness) to $8,550.86 \mathrm{kN}$ in the ANS-S3 model (most soil stiffness). Similarly, from 11,080.98 kN in the SAP-S0 model (less soil stiffness) to $8,274.16 \mathrm{kN}$ in the SAP-S3 model (most soil stiffness). This reduction is because a larger portion of the vertical load applied to the pile cap goes directly to the soil with the increase in its stiffness, reducing the fraction destined for the piles. Thus, based on this figure it can be observed that the portion of the load destined to the soil represents a percentage value of (in relation to the models without soil): $5.59 \%, 13.48 \%$ and $24.20 \%$, for the ANS-S1, ANS -S2 and ANS-S3 models, respectively; and 5.33\%, 13.95\% and 25.33\%, for the SAP-S1, SAP-S2 and SAP-S3 models, respectively. These results corroborate the affirmation made earlier that the absence of soil in the model can lead to results that are contrary to safety in the presence of the moments in the system.

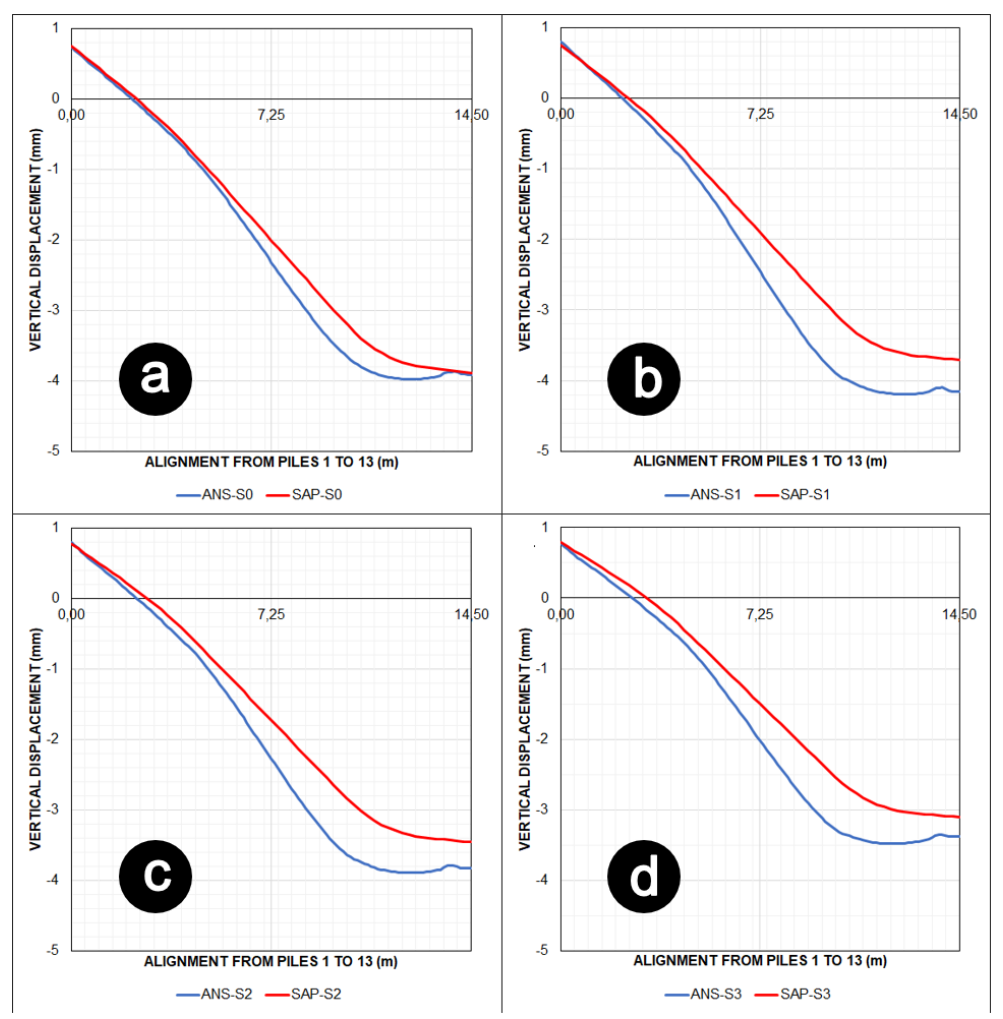

Figure 10. Comparisons between pairs of equivalent ANS-SAP models about the vertical displacement of the base of the pile cap long the alignment from piles 1 to 13: ANS-S0 and SAP-S0 (a); ANS-S1 and SAP-S1 (b); ANS-S2 and SAP-S2 (c); ANS-S3 and SAP-S3 (d). 
In Figure 10, which shows comparisons between pairs of equivalent ANS-SAP models about the vertical displacement of the pile cap base along the alignment from piles 1 to 13 , it is observed that this displacement decreases, in the module, with the increased soil stiffness. It can be verified that the displacements at the left end of the pile cap $(0.00 \mathrm{~m})$ presented compatible values for the equivalent ANS-SAP models. At the opposite end $(14.50 \mathrm{~m})$, the ANS-S0 and SAP-S0 models showed almost coincidental vertical displacements, while in the other cases, the ANS models indicated vertical displacement in the order of $10 \%$, higher (in the module) than the equivalent SAP models.

Figure 11 shows the normal radial stresses $\left(\mathrm{S}_{11}\right)$ at the base of the pile cap for the ANS-S0 and SAP-S0 models. Figure 12 shows the principal stress vector for the ANS-S0 model in a section of the pile cap along the alignment from piles 1 to 13. This stress field can be used, for example, to support a strut-and-tie model, which cannot be observed in the SAP models.
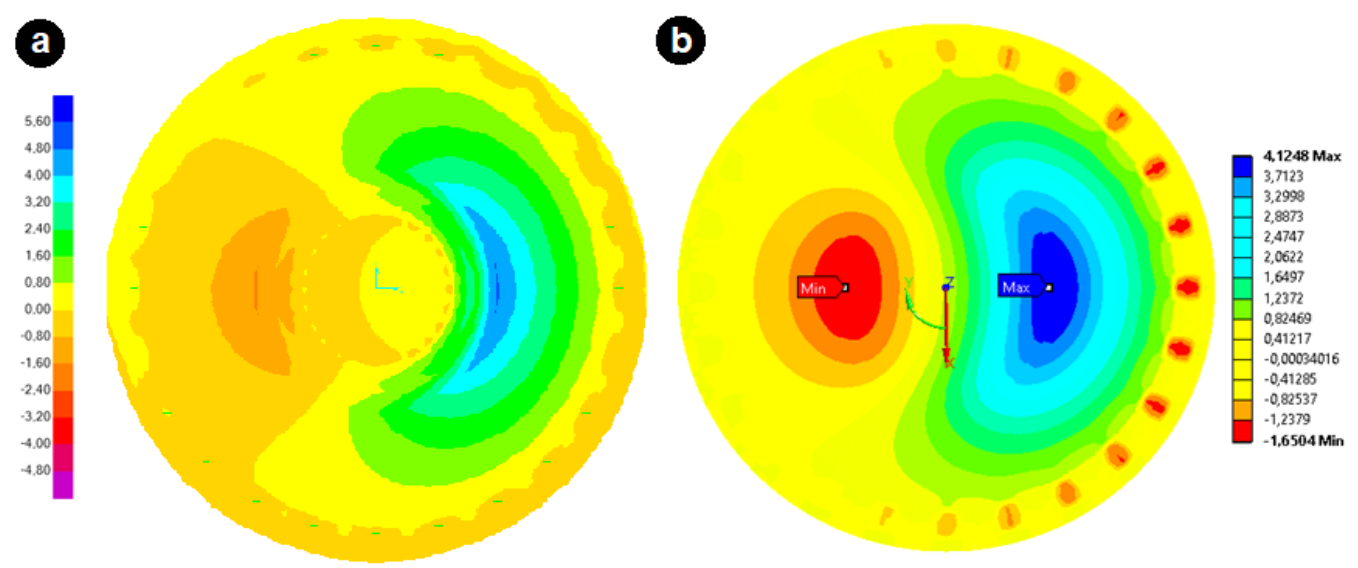

Figure 11. Normal radial stresses ( $\left.\mathrm{S}_{11}\right)$ - in $\mathrm{MPa}$ - at the base of the pile cap for the SAP-S0 (a) and ANS-S0 (b) models.

Table 5 summarizes the values of the normal radial stresses at the lower (elevation: $0 \mathrm{~m}$ ) and upper (elevation: $1.80 \mathrm{~m}$ ) ends of the pile cap, on the $\mathrm{L}$ and $\mathrm{R}$ lines, shown previously in Figure 12.

Table 5. Comparison between the normal radial stresses (MPa) of all the ANS and SAP models along the alignment from piles 1 to 13.

\begin{tabular}{|c|c|c|c|c|c|c|c|c|}
\hline \multirow{2}{*}{ Elev. (m) } & \multicolumn{8}{|c|}{ Normal Radial Stress (MPa) } \\
\hline & $\mathbf{L}$ & $\mathbf{R}$ & $\mathbf{L}$ & $\mathbf{R}$ & $\mathbf{L}$ & $\mathbf{R}$ & $\mathbf{L}$ & $\mathbf{R}$ \\
\hline & \multicolumn{2}{|c|}{ ANS-S0 } & \multicolumn{2}{|c|}{ ANS-S1 } & \multicolumn{2}{|c|}{ ANS-S2 } & \multicolumn{2}{|c|}{ ANS-S3 } \\
\hline 1.80 & 3.885 & -9.607 & 3.158 & -7.649 & 3.194 & -7.499 & 3.239 & -7.297 \\
\hline \multirow[t]{2}{*}{0.00} & -1.556 & 4.074 & -1.651 & 4.068 & -1.668 & 3.971 & -1.687 & 3.841 \\
\hline & \multicolumn{2}{|c|}{ SAP-S0 } & \multicolumn{2}{|c|}{ SAP-S1 } & \multicolumn{2}{|c|}{ SAP-S2 } & \multicolumn{2}{|c|}{ SAP-S3 } \\
\hline 1.80 & 2.037 & -5.596 & 2.075 & -5.491 & 2.162 & -5.310 & 2.262 & -5.067 \\
\hline 0.00 & -2.037 & 5.596 & -2.075 & 5.491 & -2.162 & 5.310 & -2.262 & 5.067 \\
\hline
\end{tabular}

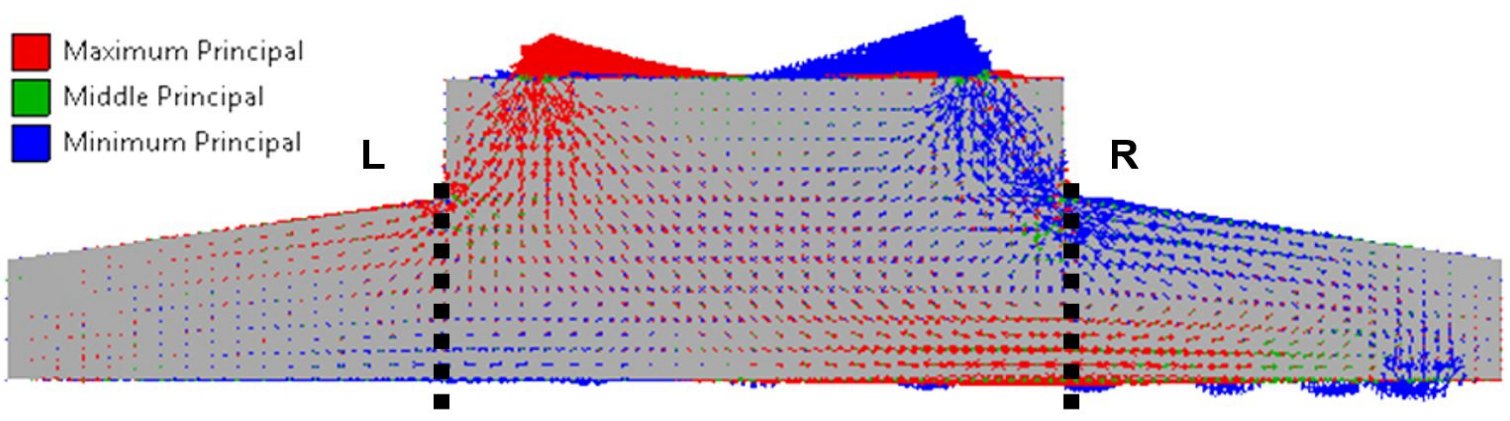

Figure 12. Principal stress vector for the ANS-S0 model in a section of the pile cap along the alignment from piles 1 to 13. 
The stress diagrams of the ANS models, shown in Figure 13, were used to calculate the resulting tensile and compression force, the length of the lever arm and the bending moment. Similarly, Figure 14 shows the equivalent diagrams for the SAP models. Analyzing Figures 13 and 14, it is observed that the normal stress diagrams of the ANS models show a different behavior from the equivalent SAP models in the region above the $1.20 \mathrm{~m}$ elevation, especially showing a non-linear stress field above the $1.60 \mathrm{~m}$ height.

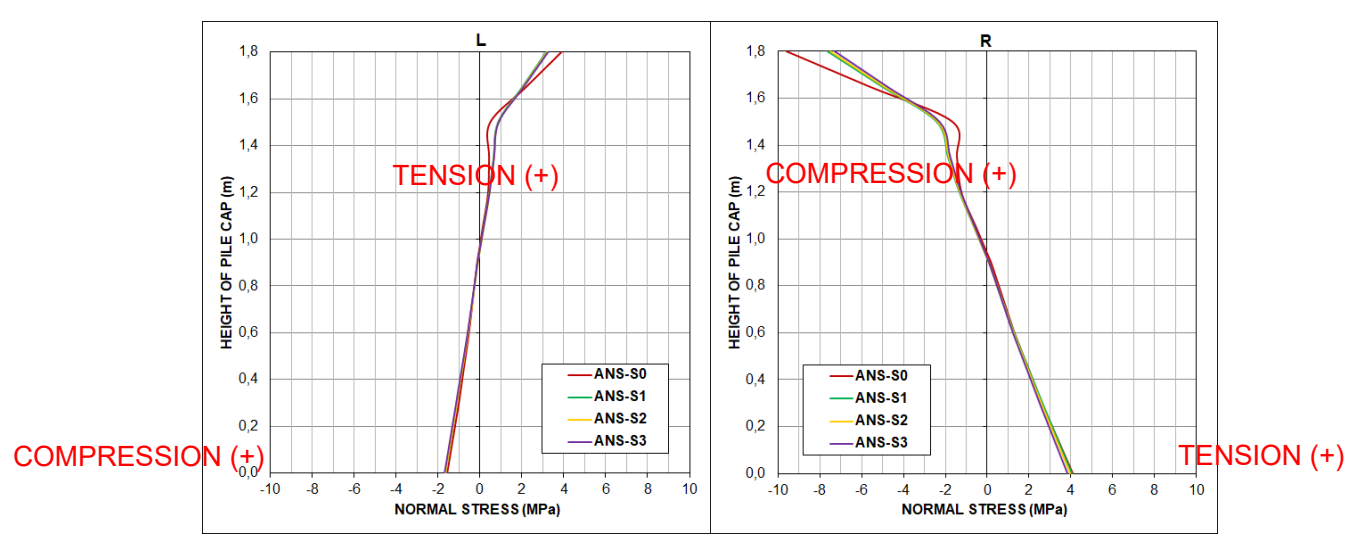

Figure 13. Stress diagrams of the ANS models in the $\mathrm{L}$ and $\mathrm{R}$ lines.
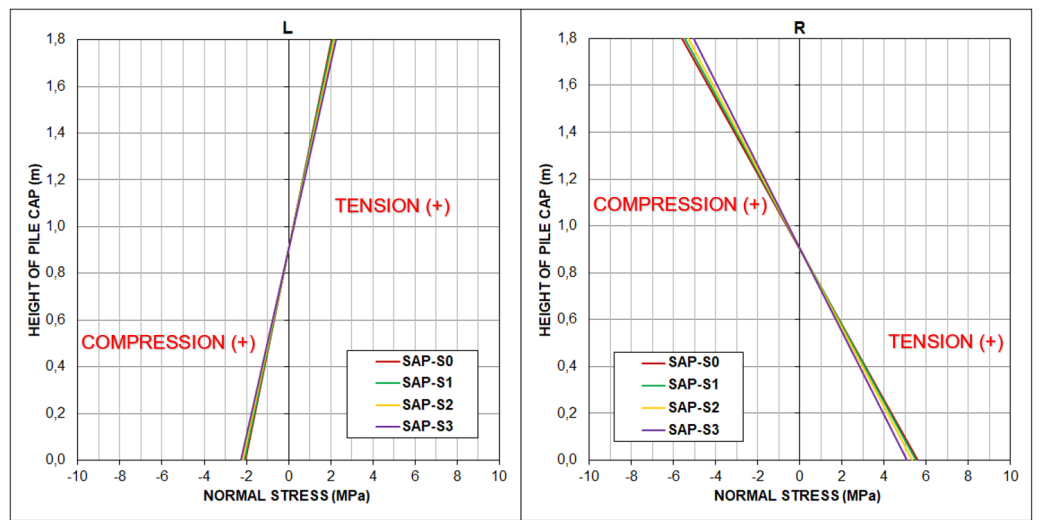

Figure 14. Stress diagrams of the SAP models in the $L$ and $R$ lines.

Table 6 shows the bending moments (around axis 2) for the ANS and SAP models, respectively, at the 4.25 and $10.25 \mathrm{~m}$ points (points equivalent to $\mathrm{L}$ and $\mathrm{R}$ lines) along the alignment from piles 1 to 13 . The bending moments of the ANS models were obtained by integrating the stress diagrams on the L and R lines. Table 6 shows that the negative bending moments of the ANS models present, on average, values in the order of $92.63 \%$ of the equivalent SAP models, with a variation coefficient of $2.84 \%$. For the positive bending moments, the average values of the ANS models are $85.21 \%$ of the equivalent SAP models, with a variation coefficient of $1.24 \%$.

Table 6. Comparison between the bending moments $(\mathrm{kN} \cdot \mathrm{m} / \mathrm{m})$ of all the ANS and SAP models along the alignment from piles 1 to 13 .

\begin{tabular}{ccccccccc}
\hline \multirow{2}{*}{$\mathbf{x}(\mathbf{m})$} & $\mathbf{9} \mathbf{M}_{\mathbf{2}}(\mathbf{k N} \cdot \mathbf{m} / \mathbf{m})$ \\
\cline { 2 - 9 } & SAP-S0 & ANS-S0 & SAP-S1 & ANS-S1 & SAP-S2 & ANS-S2 & SAP-S3 & ANS-S3 \\
\hline $4.25 / \mathrm{L}$ & -1078.78 & -994.45 & -1098.77 & -1054.27 & -1144.51 & -1062.70 & -1197.65 & -1072.53 \\
\hline $10.25 / \mathrm{R}$ & 2962.97 & 2500.09 & 2907.38 & 2455.51 & 2811.47 & 2399.57 & 2682.79 & 2324.46 \\
\hline
\end{tabular}

From the results presented, it can be concluded that the differences observed between the pairs of equivalent models (e.g., ANS-S1 and SAP-S1) were due to the type of finite element used in each of the models, especially for modeling 
the soil and the piles, in which the ANS models were modeled with solid elements, whereas in the SAP models they were represented by discrete springs.

The models produced of shell elements and springs instead of solid elements, considerably reducing the computational processing time. On the other hand, because they are more simplified, the SAP models showed more conservative results, indicating higher reaction values in the piles (in module) than those found in the equivalent ANS models, considering the most compressed pile (1) and the pile with the highest tensile strength (13).

\section{CONCLUSIONS}

It was observed that the reactions in the piles for the ANS-S0 and SAP-S0 models presented values close to each other, as well as those calculated by the analytical approach proposed by Schiel [16].

The equivalent ANS and SAP models, with soil, presented similar relative values for the portion of the load destined to the soil: $5.59 \%, 13.48 \%$ and $24.20 \%$, for the ANS-S1, ANS-S2 and ANS-S3 models, respectively; and, $5.33 \%$, $13.95 \%$ and $25.33 \%$, for the SAP-S1, SAP-S2 and SAP-S3 models, respectively.

Analyzing the reactions in the piles soliciting more efforts, the SAP models showed more conservative results, indicating values higher than those of the equivalent ANS models. This was due to the more simplified modeling adopted for the soil and for the structural elements (pile cap and piles) for the SAP models. From this perspective, it is recommended that similar pile caps, with relevant discontinuities, and those with higher relative height that are classified as rigid, should be analyzed as a three-dimensional stress problem, as well as propose a strut-and-tie model for analysis and designing based on the stress field.

In some models, the numerical analyses showed results that are contrary to the structural safety of the foundation when the presence of the soil under the pile cap base was not considered, which allows to observe an increasing tensile modulus tendency for the reaction in piles with increasing soil stiffness. This finding was better observed in the SAP models.

It was observed that the discontinued region of the pile cap (between the base and the sloping part) presented a structural behavior which does not apply the classical hypothesis of the flat cross sections of Navier-Bernoulli, due to the great distortions experienced by the structure in this region. This observation was observed through the stress diagrams of the ANS models, which did not show a linear variation along the height of the L and R lines, especially in the pile cap section above the $1.20-\mathrm{m}$ elevation. From this perspective, it is recommended that similar pile caps, with relevant discontinuities, and those with a higher relative height that are classified as rigid, should be analyzed as a threedimensional stress problem, as well as it is recommended that strut-and-tie models should be used for the analysis and designing based on the stress field.

\section{ACKNOWLEDGMENTS}

To the Civil Engineering Graduate Program of the Federal University of Rio Grande do Norte and the CAPES. This paper was carried out with support from CAPES (Coordination for the Improvement of Higher Education Personnel) Financing Code 001.

\section{REFERENCES}

[1] F. M. Sinclair and B. R. Clayton, "Excitation and damping forces on offshore wind turbines," Wind Eng., vol. 13, no. 6, pp. 276-292, 1989.

[2] J. van der Tempel and D. P. Molenaar, "Wind turbine structural dynamics - a review of the principles for modern power generation, onshore and offshore," Wind Eng., vol. 26, no. 4, pp. 211-220, 2002.

[3] S. Adhikari and S. Bhattacharya, "Dynamic analysis of wind turbine towers on flexible foundations," Shock Vib., vol. 19, pp. 37-56, 2012.

[4] M. A. Satari and S. S. E. Hussain, "Vibration based wind turbine tower foundation design utilizing soil-foundation-structure interaction," in The 14th World Conf. Earthq. Eng., Pequim, China, 2008.

[5] A. S. Moura, S. Dantas, and M. F. P. Aguiar, "A comparative study of vibration frequency estimates of the surface foundations of wind turbines built on the sand dunes of the Ceará coast," Dewi Magazin, no. 33, 2008.

[6] A. R. Ribeiro, S. S. Lima, and S. H. C. Santos, "Análise de fadiga em estrutura de fundação de torre de turbina eólica," in An. VII Cong. Bras. Pontes e Estrut., 2014.

[7] C. A. M. Araújo, A. Puel, and A. Candemil, “Análise numérica de fundações diretas de aerogeradores," in An. VII Cong. Bras. Pontes e Estruturas, Rio de Janeiro, 2014. 
[8] G. M. Maranhão, “Análise da rigidez rotacional de fundações estaqueadas de torres eólicas,” in An. IX Cong. Bras. Pontes e Estrut., Rio de Janeiro, 2016.

[9] D. A. Velloso and F. R. Lopes, Fundações - Critérios de Projeto, Investigação do Subsolo, Fundações Superficiais, Fundações Profundas. São Paulo: Oficina de Textos, 2011.

[10] A. E. H. Love, Mathematical Theory of Elasticity. New York: Dover Publications, 1944.

[11] Associação Brasileira de Normas Técnicas, Design of Concrete Structures - Procedure, ABNT NBR 6118, 2014.

[12] H. G. Poulos, "Stresses and displacements in an elastic layer underlain by rough rigid base," Geotechnique, vol. 17, pp. 378-410, 1967.

[13] H. G. Poulos and E. H. Davis, Elastic Solutions for Soil and Rock Mass. New York: John Wiley \& Sons, 1974.

[14] A. H. Teixeira and N. S. Godoy, “Análise, projeto e execução de fundações rasas," in Fundações - Teoria e Prática, W. Hachich, et al., Ed., 2a . ed. São Paulo: Pini, 1998. cap. 7, p. 227-264.

[15] J. Boussinesq, Application des POTENTIELS à L'étude de L'équilibre et du Mouvements des Solides Élastiques. Paris: GauthierVillars, 1885.

[16] F. Schiel, Estática das Construções (Publicação 10). São Carlos: Esc. Eng. São Carlos, Univ. São Paulo, 1957.

[17] U. R. Alonso, Exercício de Fundações. São Paulo: Edgard Blücher, 1983. pp. 77-78.

Author contributions: KYMA: conceptualization, numerical analysis, manuscript writing; R B: methodology, supervision, formal analysis, manuscript review; JANN: formal analysis, manuscript review.

Editors: Antonio Carlos dos Santos, José Luiz Antunes de Oliveira e Sousa, Guilherme Aris Parsekian. 